\title{
Investigating the Factors affecting the Self-care Behaviors Status of Patients with Type II diabetes and the Role of Demographic Variables: A Case Study in Iran
}

\section{Neda Kianipour}

Kermanshah University of Medical Sciences

\section{Fakhroddin Chaboksavar}

Babol University of Medical Science

Mehrali Rahimi

Kermanshah University of Medical Sciences

Javad Yoosefi Lebni

Lorestan University of Medical Sciences

\section{Jaffar Abbas}

Shanghai Jiao Tong University Laboratory for Germ Cell Research: Shanghai Jiao Tong University School of Medicine

Arash Ziapour ( $\nabla$ arashziapoor@gmail.com )

Kermanshah University of Medical Sciences https://orcid.org/0000-0001-8687-7484

\section{Research}

Keywords: Type II diabetes, self-care behaviors, factors, Iran

Posted Date: April 6th, 2021

DOI: https://doi.org/10.21203/rs.3.rs-320793/v2

License: (a) (i) This work is licensed under a Creative Commons Attribution 4.0 International License. Read Full License 


\section{Abstract}

Background: Self-care practices in diabetes patients are crucial to keep the illness under control and prevent complications. Effective management of diabetes will be a difficult task without an adequate understanding of the current level of practice related to diabetes self-care. Therefore, this study aims to assess the factors affecting the self-care behaviors status of patients with Type II diabetes and the role of demographic variables in Iran.

Methods: The present study is a descriptive-analytical study that was designed and conducted in 2020 . This study's statistical population was type II diabetic patients at the Diabetes Research Center of Ayatollah Taleghani Hospital in Kermanshah who were selected by available sampling method of 280 samples. Data collection tools included demographic characteristics questionnaire and standard selfcare questionnaire for the Glasgow and Tobert diabetic patients. Data were analyzed using SPSS-23 software, independent t-tests, one-way analysis of variance, and stepwise regression.

Results: The mean of self-care scores was $2.07 \pm 2.08$ and indicated an unfavorable condition. The highest mean scores of self-care were in the field of regular use of medications, and the lowest scores were in the field of blood-glucose testing. The mean scores of self-care were significantly different based on marital status, occupation status, residence, type of treatment, duration of diabetes, years, smoking status $(\mathrm{P}<0.05)$. Regression results showed that the variables predictors; type of treatment, smoking status, the complication of diabetes, education level status, place of residence explained $515 \%$ of the variance of self-care.

Conclusion: The study showed that the extent to which individuals adhere to Type II diabetes recommended management is substantially low. Improving awareness of patients and the community at large is imperative, especially on the diet, exercise, blood-glucose testing, foot care, and no smoking.

\section{Background}

Type II diabetes demands considerable self-management in patients' daily lives to prevent severe morbidity and mortality [1]. They are first required to learn the necessity of practicing self-care practices and then acquire the knowledge, skills, and confidence necessary to participate in their treatment actively[2]. Self-care in diabetes is an evolutionary process of developing understanding or awareness by learning to survive with the disease's complex nature in a social context[3]. Self-care in diabetes includes seven essential activities, which predict the outcome of treatment, such as eating healthy diets, practicing physical exercise, monitoring of blood sugar, adherence to medications, good problem-solving skills, healthy coping skills, and risk-reduction behavior[4].

Consistent implementation of recommended self-care behaviors for individuals with Type II diabetes requires collaboration between the patient and the provider to enable the health care system with adequate facilities and resources[5]. Self-management is considered the foundation of diabetes care, and it is believed that improving patient self-management could be through self-efficacy improvement[6]. Self- 
care behaviors refer to the decisions and measures individuals take to control their healthcare problems[7].

It is essential for those who have Type II diabetes to manage self-care behaviors to optimize their treatment outcomes[8]. Some studies investigated the relationship between health literacy and self-care behaviors [9-11] and reported discrepant results. Reisi et al. concluded that self-care behaviors were significantly associated with health literacy. Moreover, health literacy was associated with self-care behaviors such as adhering to a diet, performing physical activities, monitoring blood glucose levels, and foot care. Among the different dimensions of health literacy, communicative health literacy was acknowledged as a better predictor of self-care behaviors in diabetic patients[12].

Nevertheless, Seyedoshohadaee et al. (2015) found no significant correlation between health literacy and self-care behaviors[13]. Several studies suggest that health literacy $(\mathrm{HL})$ plays a significant role in adherence to diabetes self-care and outcomes[14, 15]. As patients are required to participate in more complicated health care and navigate more complex health systems, their need to be 'health literate' in today's society is more significant than ever before[16].

Notwithstanding the general agreement on the advantages of self-care behaviors, former literature has shown that most Iranian patients with T2DM did not properly reform self-care activities. Only $15.1 \%$ had good adherence to self-care behaviors [16].

Since individuals' self-care status is the most important determinant of diabetes control, in different cultural contexts, the rate of observance and performance of self-care behaviors differs from each other. It is a concept that needs further study. This study aimed to investigate the Factors Affecting the self-care behaviors Status of Patients with Type II Diabetes and the Role of Demographic Variables.

\section{Type II diabetes}

The World Health Organization describes diabetes as a metabolic disorder of various etiologies characterized by chronic hyperglycemia with irregularities of carbohydrate, fat, and protein metabolism that occurs from insulin secretion, insulin action, or both[6].

Diabetes is a lifelong disease, and its self-management is challenging, time-consuming, and life-long, posing a challenge throughout life[17-19]. More than 425 million people continued living with diabetes in 2017, and people with diabetes are predicted to extend to 693 million by 2045[20,21]. It is calculated that there will be 300 million diabetes people by 2025[11], and by 2030, around 366 million people will have type II diabetes mellitus[9]. The prevalence of diabetes in Iran is 3.0, 5.8, 10.8, 14.0\% in men and 3.0, 7.0, 14.0 , and $19.4 \%$ in women aged $25-34,35-44,45-54$, and 55-64 years, respectively[16]. It has been predicted that around $11.4 \%$ of the Iranian adult population has diabetes mellitus, and by 2030 , around 9 million Iranians will be at risk of developing diabetes mellitus[15]. Approximately $80 \%$ of diabetic patients in developing countries live in deprived and less developed regions[15]. 
Diabetes is a lifetime condition and leads to chronic difficulties if blood glucose is raised continuously[22, 23]. Living with diabetes changes all aspects of a patient's life; the patient can have an everyday life if they do self-care activities intended to control their symptoms and avoid long-term complexities[24]. The target therapeutic goals' achievement requires constant monitoring of blood sugar, stern adherence to lifestyle measures and medications, and ongoing management to stop complications. Therapeutic goal achievement also demands a high ability to endure the psychosocial difficulties associated with living with the disease and dynamically consuming appropriate diabetes support services[22]. Multiple factors can influence glycemic control, related to the patient, the disease, and the treatment[25]. Global studies documented a high prevalence of uncontrolled diabetes with various factors implicated in low blood sugar control[3, 22, 25].

HL's need becomes more complicated among patients with T2D because they have to manage their diet and control their blood sugar for the rest of their lives. Making considerable lifestyle HL's interpreting, analyzing, reading self-care changes is not an easy undertaking. Therefore, patients with T2D have to learn self-care management and high medication adherence, including reading, analyzing, and interpreting nutrition and medication labels[3]. Health management problems are more apparent in individuals with limited HL[13]. Patients with limited health numeracy are more likely to have high BMI and poor glycemic control $[10,26]$ and less likely to have good diabetes management[13]. Limited HL is associated with increased hospitalization rates among patients with diabetes[11]. There is evidence of a close relationship between low health status, poor disease management, poor self-care, and limited HL among diabetic patients[15]. Diabetic patients with adequate $\mathrm{HL}$ are more likely to manage their insulin doses[27] and are prone to read and interpret medication labels correctly[28]. Other factors that can affect individuals' knowledge, information, and HL skills include socio-demographic and cultural characteristics, lifestyle, and environmental influences. Age, race, educational level, and income can affect the individual's capacity to read, understand and use health information to make the right health decisions. Other factors can also affect HL levels, including limited communication skills. This limitation influences the individual's ability to navigate through the health care system, which paves the way for them to understand health-related issues communicate with health care providers, explain the symptoms clearly, and accurately fill personal and health history forms[29].

\section{Methods}

\section{Study Setting and Participants}

This study employed a cross-sectional descriptive-analytical design from January 1 st and July 30th, 2020. Non-probabilistic sample of 280 patients with T2D at the Diabetes Research Center of Ayatollah Taleghani Hospital in Kermanshah was approached. The sample was selected and analyzed by available sampling method from patients referred to health centers. According to previous studies, to determine the sample size and using Cochran's formula and considering $a=0.5$ and $d=0.5,280$ people were estimated.

\section{Inclusion and Exclusion Criteria}


Inclusion criteria were adult age (20 years), diagnosed with Type II diabetes for more than one year having sufficient language skills-participants studied patients' self-care status that were willing to participate in the study and gave written informed consent. Patients who have cognitive, mental, or physical problems, complications that might affect their ability to perform diabetes self-management activities, such as blindness, end, stage renal disease, and limb amputation, can prevent them from completing the questionnaire.

\section{Informed consent}

All participants were fully informed of the study aim and methodology and signed an informed consent form before inclusion in the study. They were reassured of the study's complete confidentiality and reassured that all the published data would be anonymous. Only researchers had access to research data.

\section{Ethics statement}

This study was conducted in accordance with the Declaration of Helsinki. All participants were told before the investigation, and participants themselves signed consent forms. The ethics committee approved that consent forms can be signed by their relatives or data collectors at the participants' request for those who can't sign their names. Participants were made aware that all data would remain anonymous.

\section{Data collection}

The data was received from patients attending Primary Health Care clinics. The questionnaire included two parts:

\section{Socio-demographic questionnaire}

The socio-demographic attributes, including age, gender, marital status, educational status, occupation, average monthly income, residence, type of treatment, duration of diabetes, years, family history of diabetes, diabetes complications, abdominal obesity, smoking, were taken into account.

\section{Self-care behaviors questionnaire in patients}

A Persian version of the Summary of Diabetes Self-Care Activities (SDSCA) was devised by Toobert et al. [30] was used. This questionnaire with 12-items estimate the patients' self-care over the past seven days, covering the various aspects of self-care behaviors of patients with diabetes, including diet (items 1-4), exercise (items 5-6), blood-glucose testing (items 7-8), foot care (items 9-10), regular use of medications (items 11), and smoking status (item 12). Its Persian version's validity and reliability are recognized in the study of Didarloo et al. (37) ( $a=0.83$ ). This rating scale ranges from 0 to 84 , where a higher score indicates a better self-care performance. Cronbach's alpha was 0.82 for the full scale in our sample. 


\section{Data analyses}

The data was analyzed through the descriptive statistics (frequency, percentage, mean and standard deviation) and inferential statistics independent t-test (to compare the means of a quantitative variable in two separate groups) (e.g., gender, residence, family history of diabetes, diabetes complication and abdominal obesity). ANOVA was used (for comparing the means of a quantitative variable in three or more groups) (e.g., age, marital status, educational status, occupation, average monthly income, type of treatment, duration of diabetes, years, and smoking). The stepwise multiple regressions were also used to predict health literacy based on the Demographic Variables. All tests were analyzed through the SPSS version 23 software (version 23.0, SPSS Inc., Chicago, IL, USA) at the significance level of $0.05(p<0.001)$.

\section{Results}

\section{Characteristics of the Study Population}

Of the 280 patients in the study, $53.2 \%$ were female, and $46.8 \%$ were male. The subjects' age range was between 23 and 88 years, and the average and standard deviation of the research units' age was $55.80 \pm 13.04$ years. The highest frequency of patients' age group was related to the age group (69-60 years) with $26.1 \%$, and the lowest value was in the group (18-29 years) with $1.4 \% .76 .8 \%$ of the participants were married, and the rest were single, widowed, or divorced. In terms of education, $33.6 \%$ were illiterate, $41.8 \%$ had undergraduate education, and $12.5 \%$ had a diploma and $12.1 \%$ higher than a diploma. $48.2 \%$ were homeowners, $17.5 \%$ were workers, $8.6 \%$ were government employees, $12.9 \%$ were self-employed, and $12.9 \%$ were retired. The highest level of the respondents' income (39.6\%) was between one million and two million, and the lowest level of income of $30 \%$ of the participants was less than 1 million Rial. $95 \%$ of the people lived in the city and $5 \%$ in the village. In terms of treatment, $22.1 \%$ of the participants used diet, $57.1 \%$ used the pill, $18.2 \%$ used insulin, and $2.5 \%$ used medication and insulin to control it. In terms of duration of diabetes, $50 \%$ had abdominal obesity less than five years and $29.3 \%$ between $6-10$ years, and 168 people had $60 \%$ abdominal obesity. $16.8 \%$ of the participants were smokers, $5 \%$ smoked before, and (75.7\%) of the respondents did not smoke at all (Table 1).

The mean and standard deviation of type II diabetic patients' self-care behaviors score was $2.07 \pm 1.08$, which showed an unfavorable condition. The results of patients' self-care behavioral indices are shown separately in Table 2. The independent t-test showed that self-care behaviors in diabetic patients of rural residents are more than those of urban residents, and a significant relationship was recorded $(p<0.000)$. One-way analysis of variance showed a significant relationship between self-care behaviors of diabetic patients with marital status, occupation status, type of treatment, duration of diabetes, years, and smoking status $(p<0.000)$. (Table 2$)$

Multiple linear regression analysis was conducted to identify patients' demographic predictors for diabetes-related self-care activities (SCBQ sub-scale score). Regression analysis showed that patients' type of treatment $(\beta=0.453 ; 95 \% \mathrm{Cl}-0.182,0.083)$, smoking status $(\beta=-0.219 ; 95 \% \mathrm{Cl}-0.310,0.074)$, complication of diabetes $(\beta=-0.189 ; 95 \% \mathrm{Cl} 0.442,0.310)$, educational status $(\beta=-0.145 ; 95 \% \mathrm{Cl} 0.160$, 
$0.060)$, and place of residence $(\beta=0.118 ; 95 \% \mathrm{Cl} 0.584,0.261)$ were significant predictors for their selfcare activities. Whereas patients' gender, age, marital status, occupation status, average monthly income, duration of diabetes, years, family history of diabetes, and abdominal obesity were insignificant predictors for patients' self-care activities. The details are displayed in Table 3.

Table 1 Sociodemographic and economic characteristics of the study participants $(n=280)$ 


\begin{tabular}{|c|c|c|c|c|c|}
\hline Variables & Category & $\begin{array}{l}\text { Frequency } \\
\text { (\%) }\end{array}$ & $\begin{array}{l}\text { Mean } \pm \\
\text { SD }\end{array}$ & $\begin{array}{l}\text { Statistical } \\
\text { test }\end{array}$ & $\begin{array}{l}\mathrm{P}- \\
\text { value }\end{array}$ \\
\hline \multirow[t]{2}{*}{ Gender } & Male & $\begin{array}{l}131 \\
(46.8 \%)\end{array}$ & $2.13 \pm 1$ & \multirow[t]{2}{*}{$\begin{array}{l}\text { Independent } \\
\text { t-test }\end{array}$} & \multirow[t]{2}{*}{0.451} \\
\hline & Female & $\begin{array}{l}149 \\
(53.2 \%)\end{array}$ & $2.03 \pm 1$ & & \\
\hline Age & $18-29$ & $4(1.4 \%)$ & $3.58 \pm 0.61$ & \multirow{7}{*}{$\begin{array}{l}\text { One-way } \\
\text { ANOVA }\end{array}$} & \multirow[t]{7}{*}{0.125} \\
\hline \multirow[t]{6}{*}{$55.80 \pm 13.04$} & $30-39$ & $\begin{array}{l}31 \\
(11.1 \%)\end{array}$ & $2.23 \pm 1$ & & \\
\hline & $40-49$ & $\begin{array}{l}62 \\
(22.1 \%)\end{array}$ & $1.96 \pm 1$ & & \\
\hline & $50-59$ & $\begin{array}{l}65 \\
(23.2 \%)\end{array}$ & $2.05 \pm 1$ & & \\
\hline & $60-69$ & $\begin{array}{l}73 \\
(26.1 \%)\end{array}$ & $2.09 \pm 1.1$ & & \\
\hline & $70-79$ & $\begin{array}{l}34 \\
(12.1 \%)\end{array}$ & $1.97 \pm 1$ & & \\
\hline & $>80$ & $11(3.9 \%)$ & $2.29 \pm 0.60$ & & \\
\hline \multirow[t]{4}{*}{ Marital status } & Single & $20) 7.1 \%)$ & $2.50 \pm 1.2$ & \multirow{4}{*}{$\begin{array}{l}\text { One-way } \\
\text { ANOVA }\end{array}$} & \multirow[t]{4}{*}{0.049} \\
\hline & Married & $\begin{array}{l}215 \\
(76.8 \%)\end{array}$ & $2.11 \pm 1$ & & \\
\hline & Divorced & $6(2.1 \%)$ & $1.51 \pm 1.2$ & & \\
\hline & Windowed & $3(13.9 \%)$ & $1.79 \pm 0.94$ & & \\
\hline \multirow[t]{4}{*}{ Educational status } & illiterate & $\begin{array}{l}94 \\
(33.6 \%)\end{array}$ & $1.93 \pm 1$ & \multirow[t]{4}{*}{$\begin{array}{l}\text { One-way } \\
\text { ANOVA }\end{array}$} & \multirow[t]{4}{*}{0.224} \\
\hline & High school & $\begin{array}{l}117 \\
(41.8 \%)\end{array}$ & $2.11 \pm 1.1$ & & \\
\hline & Diploma & $\begin{array}{l}35 \\
(12.5 \%)\end{array}$ & $2.14 \pm 0.96$ & & \\
\hline & Above diploma & $\begin{array}{l}34 \\
(12.1 \%)\end{array}$ & $2.36 \pm 0.87$ & & \\
\hline \multirow[t]{3}{*}{ Occupation status } & Housewife & $\begin{array}{l}135 \\
(48.2 \%)\end{array}$ & $2.03 \pm 1.1$ & \multirow[t]{3}{*}{$\begin{array}{l}\text { One-way } \\
\text { ANOVA }\end{array}$} & \multirow[t]{3}{*}{0.046} \\
\hline & worker & $\begin{array}{l}49 \\
(17.5 \%)\end{array}$ & $1.79 \pm 1$ & & \\
\hline & $\begin{array}{l}\text { Government } \\
\text { employ }\end{array}$ & $24(8.6 \%)$ & $2.24 \pm 0.73$ & & \\
\hline
\end{tabular}




\begin{tabular}{|c|c|c|c|c|c|}
\hline & Self-employed & $\begin{array}{l}36 \\
(12.9 \%)\end{array}$ & $2.21 \pm 0.98$ & & \\
\hline & Retired & $\begin{array}{l}36 \\
(12.9 \%)\end{array}$ & $2.43 \pm 1$ & & \\
\hline \multirow{3}{*}{$\begin{array}{l}\text { Average monthly income } \\
\text { Household income per capita, } \\
\text { USD dollars }\end{array}$} & $<1$ million & $84(30 \%)$ & $1.88 \pm 1$ & \multirow{3}{*}{$\begin{array}{l}\text { One-way } \\
\text { ANOVA }\end{array}$} & \multirow[t]{3}{*}{0.107} \\
\hline & 1 at 2 million & $\begin{array}{l}111 \\
(39.6 \%)\end{array}$ & $2.14 \pm 1.2$ & & \\
\hline & $>2$ million & $\begin{array}{l}85 \\
(30.4 \%)\end{array}$ & $2.20 \pm 0.84$ & & \\
\hline \multirow[t]{2}{*}{ Place of Residence } & Urban & $266(95 \%)$ & $2.04 \pm 1$ & \multirow{2}{*}{$\begin{array}{l}\text { Independent } \\
\text { t-test }\end{array}$} & \multirow[t]{2}{*}{0.000} \\
\hline & Rural & $14(5 \%)$ & $2.89 \pm 1$ & & \\
\hline \multirow[t]{4}{*}{ Type of treatment } & diet & $\begin{array}{l}62 \\
(22.1 \%)\end{array}$ & $1.14 \pm 0.85$ & \multirow[t]{4}{*}{$\begin{array}{l}\text { One-way } \\
\text { ANOVA }\end{array}$} & \multirow[t]{4}{*}{0.000} \\
\hline & Tablet & $\begin{array}{l}160 \\
(57.1 \%)\end{array}$ & $2.34 \pm 0.99$ & & \\
\hline & Insulin & $\begin{array}{l}51 \\
(18.2 \%)\end{array}$ & $2.32 \pm 0.94$ & & \\
\hline & $\begin{array}{l}\text { Tablets and } \\
\text { insulin }\end{array}$ & $7(2.5 \%)$ & $2.80 \pm 1$ & & \\
\hline \multirow[t]{3}{*}{ Duration of diabetes, years } & $<5$ & $140(50 \%)$ & $1.83 \pm 1$ & \multirow{3}{*}{$\begin{array}{l}\text { One-way } \\
\text { ANOVA }\end{array}$} & \multirow[t]{3}{*}{0.001} \\
\hline & $6-10$ & $\begin{array}{l}82 \\
(29.3 \%)\end{array}$ & $2.36 \pm 1.1$ & & \\
\hline & $>10$ & $\begin{array}{l}58 \\
(20.7 \%)\end{array}$ & $2.28 \pm 0.94$ & & \\
\hline \multirow[t]{2}{*}{ Family history of diabetes } & Yes & $\begin{array}{l}181 \\
(64.6 \%)\end{array}$ & $2.03 \pm 0.99$ & \multirow[t]{2}{*}{$\begin{array}{l}\text { Independent } \\
\text { t-test }\end{array}$} & \multirow[t]{2}{*}{0.316} \\
\hline & No & $\begin{array}{l}99 \\
(35.4 \%)\end{array}$ & $2.17 \pm 1.2$ & & \\
\hline \multirow[t]{2}{*}{ Complication of diabetes } & Yes & $\begin{array}{l}86 \\
(30.7 \%)\end{array}$ & $1.96 \pm 0.85$ & \multirow[t]{2}{*}{$\begin{array}{l}\text { Independent } \\
\text { t-test }\end{array}$} & \multirow[t]{2}{*}{0.165} \\
\hline & No & $\begin{array}{l}194 \\
(69.3 \%)\end{array}$ & $2.13 \pm 1.1$ & & \\
\hline \multirow[t]{2}{*}{ Abdominal obesity } & Yes & $168(60 \%)$ & $2.06 \pm 1$ & \multirow{2}{*}{$\begin{array}{l}\text { Independent } \\
\text { t-test }\end{array}$} & \multirow[t]{2}{*}{0.759} \\
\hline & No & $112(40 \%)$ & $2.10 \pm 1$ & & \\
\hline \multirow[t]{2}{*}{ Smoking status } & Yes, smoke & $\begin{array}{l}47 \\
(16.8 \%)\end{array}$ & $2.61 \pm 1$ & \multirow[t]{2}{*}{$\begin{array}{l}\text { One-way } \\
\text { ANOVA }\end{array}$} & \multirow[t]{2}{*}{0.001} \\
\hline & $\begin{array}{l}\text { Yes, before } \\
\text { smoke }\end{array}$ & $21(.5 \%)$ & $1.80 \pm 1.1$ & & \\
\hline
\end{tabular}


$N(\%)=$ Frequency $/$ Percent

Table 2- Mean and standard deviation of Self-Care Behaviors

\begin{tabular}{|lllll|}
\hline Self-Care Behaviors & $\begin{array}{l}\text { Number of } \\
\text { items }\end{array}$ & $\begin{array}{l}\text { Self-care score (day to week) Mean } \\
\mathbf{\pm S D}\end{array}$ & Max & Min \\
\hline Diet & 4 & $2.71 \pm 1.3$ & 0 & 7 \\
\hline Exercise & 2 & $1.52 \pm 1.6$ & 0 & 7 \\
\hline Blood-glucose testing & 2 & $1.12 \pm 1.5$ & 0 & 7 \\
\hline Foot care & 2 & $1.35 \pm 2$ & 0 & 7 \\
\hline Regular use of medications & 1 & $4.16 \pm 2.8$ & 0 & 7 \\
\hline Smoking status & 1 & $1.17 \pm 2.5$ & 0 & 7 \\
\hline $\begin{array}{l}\text { Total score of Self-Care } \\
\text { Behaviors }\end{array}$ & - & $2.08 \pm 1.07$ & 0 & 6.46 \\
\hline
\end{tabular}

$\mathrm{SD}=$ standard deviation, $\mathrm{Max}=$ maximum, $\mathrm{Min}=$ minimum

Table 3- Linear association of patients' demographic characteristics on SCBQ sum scale

\begin{tabular}{|llll|}
\hline Predictors & $\boldsymbol{\beta}$ & $\mathbf{( 9 5 \% ~ C l}$ & P-value \\
\hline Type of treatment & 0.453 & $-0.182,0.083$ & 0.000 \\
\hline Smoking status & -0.219 & $-0.310,0.074$ & 0.000 \\
\hline Complication of diabetes & 0.189 & $0.442,0.130$ & 0.001 \\
\hline Educational status & 0.145 & $0.160,0.060$ & 0.008 \\
\hline Place of Residence & 0.118 & $0.584,0.261$ & 0.026 \\
\hline
\end{tabular}

Abbreviation: SCBQ, Self-Behavior Questionnaire. Cl, Confidence Interval.

\section{Discussion}

Diabetes is becoming a severe health problem, especially in low- and middle-income countries such as Iran. This study aimed to investigate Investigating the Factors Affecting the self-care behaviors Status of Patients with Type II diabetes and the Role of Demographic Variables living in Kermanshah. Our study's 
findings showed that the self-care status of the studied patients was not in good condition in general, which is consistent with the results of other studies in this field [31-33]. In the studies of Anbari et al. [33], Sorani et al. [34] and Jordan et al. [35] reported low to moderate self-care of diabetic patients, which is consistent with the present study. The present study seems to have poor performance because patients in the diabetes center or health centers do not receive self-care guidance from the center and the doctor and nurses, and the media.

Among the self-care behaviors associated with diabetes, regular use of medications and diet were more common. They were due to the fear of diabetes and severe hyperglycemia, which is consistent with the results of the study of Anbari et al. [33], Nouhjah [36], and Vaezi et al. [37]. One of the reasons that can be considered for patients' acceptable performance in the use of prescribed drugs is the patients' belief in the method of disease control. Most people believe that they have to take medicine to treat the disease while believing in making some lifestyle changes to overcome the disease when they get sick. For the reasons mentioned above, it is seen that the medication has been used at an acceptable level. However, personal blood sugar measurements were at the lowest level, consistent with the study of Anbari et al. [33] and Nouhjah [36]. It should be noted that patients mentioned that not having a personal blood sugar measurement is not having a blood sugar testing device, and not using this device.

Self-care behaviors in diabetes are an essential and special need throughout life. People with diabetes need regular access to equipment such as a glucometer and blood glucose test strip to regularly measure blood sugar, despite the need for knowledge and skills in this area. It is seen that most patients with diabetes have an inability to pay the costs, lack of skills to measure blood sugar, and lack of education. Therefore, it is necessary to emphasize the intensity and seriousness of these behaviors and their possible consequences for the individual in educational programs, taking into account the above issues.

The findings showed that self-care performance lacked exercise, blood-glucose testing, foot care, and smoking status, which may be due to the difficulty of going to the laboratory or financial ability and insufficient skills to use the glomerulus. This finding is consistent with the results of a study by Vaezi et al. [37] that self-care performance in the areas of blood glucose monitoring and physical activity was low. In the study of Jordan et al. [35], the most insufficient self-care activity was in daily control of blood sugar and timely use of medication and regular physical activity, which was consistent with the present study.

According to this study's results, the average score of self-care in men, although higher than women, but this difference is not significant. In the study of Vaezi et al. [37], the results showed that self-care was more increased in men than women, which was consistent with the present study. While in the study of Shabibi et al. [32] and Farmer et al. [38], the self-care scores in female diabetic patients were significantly higher than in male patients, which was not consistent with the present study $[32,38]$.

According to Farmer et al. [38], female diabetic patients had significantly more self-care than diabetic men. However, men were expected to have lower self-care status due to less time devoted to self-care due to work, poor adherence to treatment, and more risky behaviors. In the study of Bai et al. [39], the self-care score in men was significantly higher than in women. The effect of gender difference on self-care ability 
can be affected by other variables such as knowledge level, physical-psychological, and behavioral status.

The age factor did not show a significant relationship with self-care behaviors. These findings were reported by Bukhsh et al. [40], Babazadeh et al. [41], Vaezi et al. [37], Hu et al. [42] were not aligned. It can be argued that aging reduces self-care for forgetfulness, inability, and further complications, thereby increasing the disease's severity.

In the present study, the mean scores of self-care behaviors in married patients were higher than in single patients. Still, this means the difference was significant, which may be due to the higher number of married people than a single in our study, which is consistent with Bukhsh et al. [40] Anbari et al. [33] in Iran. However, in the study of Vaezi et al. [37], Davari et al. [43], and Tal et al., it has been argued that married people face more self-care than single people because they have more social support and more knowledge.

There was no significant relationship between the levels of education of the subjects with self-care behaviors. However, people with higher levels of education had more self-care than other patients. This finding was not in line with the results of the study by Bukhsh et al. [40], Vaezi et al. [37], Hu et al. [42], Cassimatis et al. [44]. Studies show that higher education patients have better judgment and decisionmaking ability to perform self-care behaviors [36]. It can also be inferred that increasing education level by expanding the knowledge and knowledge of research units about their illness and self-care facilitates self-care [45]. In other words, with increasing education and awareness of the complications of diabetes and understanding the severity of the problem, their attitude changed, and people became more concerned about self-care, which in turn will lead to the behavior in question [36]. Thus, a high level of education facilitates the disease's self-care, while a low education level makes this process difficult.

In terms of job status, there was a significant difference between the mean score of self-care behaviors with the job so that the average self-care score of retirees was higher than others. This finding was constant with the results of the study of Babazadeh et al. [41], Bukhsh et al. [40], and Vaezi et al. [37]. It can be argued that retirees enjoy economic support, including pensions, so they are more self-reliant.

In this study, monthly household income was not significant with self-care behaviors, which was not consistent with the study of Babazadeh et al. [41], Vaezi et al. [37], Hu et al. [42], and Davari et al. [43]. The findings of Aghamalai et al.'s study [46] show that the most important reasons for not performing blood tests at home are the cost of blood sugar test kits and the patient's family's inability to provide the equipment. It can be debated that the high cost of treatment, testing, and drug shortages in society's current economic conditions causes many problems that prevent self-care behaviors.

The patients' scores were different from self-care behaviors according to location, and self-care scores of urban residents were significantly higher than rural residents, which is consistent with the findings of Anbari et al. The reason is probably the better and easier access of patients living in rural areas to medical care centers. 
Self-care varied significantly depending on the type of treatment. The mean score of self-care in patients taking pills and insulin was higher than those treated with diet. In the study of Davari et al. [43] and Huisman et al. [47], self-care behaviors varied according to the type of treatment. This is the present study can be interpreted as that person taking pills or insulin, aware of the importance of taking medications or insulin to treat disease and lowering blood sugar, so for fear of chronic complications of diabetes to take pills or injections required insulin.

The duration of diabetes was significantly associated with patients' self-care behaviors. In other words, having diabetes for a long time, a person faces more obstacles, which can be due to old age, more complications, and other chronic diseases [48]. The study by Bukhsh et al. [40], Vaezi et al. [37], and Babazadeh et al. [41] showed that with increasing duration of diabetes, patients gain more knowledge and skills in the field of self-care, and this leads to the promotion of these behaviors. However, in the study of Mohammadzadeh et al. [49] and Anbari et al. [33], there was no significant relationship between diabetes and self-care duration. Perhaps this discrepancy is the difference in the sex distribution of the present study groups with the before mentioned studies or researching different populations. There was no significant relationship between family history of diabetes and self-care behaviors, which is consistent with the study of Bukhsh et al.[40].

In the present study, the status of diabetes did not show a significant relationship with self-care behaviors, which was in line with the study of Bigdeli et al. [50]. In the present study, abdominal obesity did not show a significant relationship with self-care behaviors. On the other hand, $60 \%$ of patients had abdominal obesity, which may affect the self-care status of diabetic patients. It is usual for obese people because they do not follow their diet and do not have much physical activity; they are expected to have more inadequate self-care. These results were consistent with the study of Bigdeli et al. [50].

In this study, smoking was significant with self-care behaviors. This finding was not consistent with the study of Bukhsh et al. [40]. Smoking is a risk factor for developing diabetes, and people with diabetes who smoke are at greater risk for kidney damage, cardiovascular disease, and other diabetes-related problems[51]. These results indicate the need for further study and more appropriate education on smoking's side effects in diabetic patients.

In the present study, the findings showed that the type of treatment, smoking status, complications of diabetes, educational level, and place of residence predict $515 \%$ of the variance of self-care behaviors in patients with Type II diabetes. The strongest predictor of self-care behaviors is the variable type of treatment.

Patients seem to be looking for cost-effective and affordable treatments because of their experience with diabetes. Nouhjah [36] findings showed that the variables of how to see a doctor, level of education, life network, and duration of diabetes predict $23 \%$ of the variance in self-care behaviors of type II diabetic patients. In the present study, education was one of the predictors of self-care behaviors with which the results of several studies were consistent $[39,52,53]$. It can be argued that the best self-care practice in diabetic patients occurs when the patient has a high level of knowledge and awareness, and it is at this 
time that diabetes control improves. It seems that education in groups with lower literacy levels should be emphasized.

\section{Strength And Limitations}

A limitation of the study is its design, as cross-sectional study designs evaluate the patients at one point in time, hence cannot examine the change or improvement in patients' self-care practices. Secondly, the term "predict" in this study refers to statistical prediction using regression analyses of concurrent associations between study variables; no causal inference is possible. Another limitation of the study is the potential bias associated with self-reporting of diabetes-related self-care activities. Factors that could have influenced $\mathrm{HbA} 1 \mathrm{c}$ levels like co-morbid conditions inherited hemoglobinopathies and personal characteristics like empowerment and quality of life have not been studied and could be explored in greater depth.

\section{Conclusion}

To prevent morbidity and mortality associated with diabetes, patients' dedicated self-care activities are of crucial importance. The study showed that the extent to which individuals adhere to Type II diabetes recommended management is substantially low. Improving patient awareness and the community is imperative, especially on the diet, exercise, blood-glucose testing, foot care, and no smoking. Marital status, occupation status, residence, type of treatment, duration of diabetes, years, and smoking status were statistically significant in adherence to self-care behavior. Therefore, attention should be given to those patients with complications and low HL'ssocio-economic rates. Moreover, strategies should be developed to support patients with information, glucometer and enhance their social support.

\section{Declarations}

\section{Acknowledgment}

The authors would like to thank all the participants who patiently participated.

\section{Ethics approval and consent to participate}

The Ethics Committee of Kermanshah Faculty of Medical Sciences reviewed and approved the study protocol. All participants signed written informed consent after explanation of nature, objectives, and procedures used in the study. All questionnaires were confidential and were voluntary to the patients. Respondents were free to withdraw from the study at any time.

\section{Consent to publish}

All participants consented verbally to the publication of the interview data. 


\section{Availability of data and materials}

The datasets using in the study are available from the corresponding author on reasonable request.

\section{Competing interests}

The authors declare that they have no competing interests.

\section{Funding}

This study did not receive any grant from funding agencies.

\section{Authors' Contributions}

All authors were responsible for the study.

AZ and NK were responsible for the study Conceptualization and led the paper's writing.

JYL and JA conducted the Literature review and assisted in writing the paper.

AZ and JA performed the analysis, assisted in interpreting the data, and writing the paper.

MAR and JYL assisted with the interpretation of the results and drafting programmatic Implications.

FC and AZ were responsible for data collection and coordination of the study.

AZ co-led the conceptualization, supervised all aspects of writing the paper, and provided extensive comments on the manuscript. All the authors have read and approved the final manuscript.

\section{Author Details}

${ }^{1}$ Students Research Committee, Kermanshah University of Medical Sciences, Kermanshah, Iran.

${ }^{2}$ Nursing Care Research Center, Health Research Institute, Babol University of Medical Sciences, Babol, I.R. Iran.

${ }^{3}$ Diabetes Research Center, Kermanshah University of Medical Sciences, Kermanshah, Iran

${ }^{4}$ Department of Social Medicine, Faculty of Medicine, Lorestan University of Medical Sciences, Khorramabad, Iran.

${ }^{5}$ Antai College of Economics and Management/School of Media and Communication, Shanghai Jiao Tong

University, Shanghai, China.

${ }^{6}$ Research Center for Environmental Determinants of Health (RCEDH), Health Institute, Kermanshah University of Medical Sciences, Kermanshah, Iran. 


\section{Abbreviations}

SCB: Self-care Behaviors;

TIID: Type II diabetes;

RD: Role of Demographic

\section{References}

1. Kato A, Fujimaki Y, Fujimori S, Isogawa A, Onishi Y, Suzuki R, et al. Association between self-stigma and self-care behaviors in patients with type 2 diabetes: a cross-sectional study. BMJ Open Diabet Res 2016;4(1):e000156.

2. Le $\mathrm{C}$, Rong S, Dingyun $\mathrm{Y}$, Wenlong $\mathrm{C}$. Socioeconomic disparities in type 2 diabetes mellitus prevalence and self-management behaviors in rural southwest China. Diabet Res Clin Pract. 2016;121:9-16.

3. Rachmawati U, Sahar J, Wati DNK. The association of diabetes literacy with self-management among older people with type 2 diabetes mellitus: a cross-sectional study. BMC Nurs. 2019;18(1):1-8.

4. Alvarado-Martel D, Ruiz Fernández $M$, Cuadrado Vigaray $M$, Carrillo $A$, Boronat $M$, Expósito Montesdeoca A, et al. Identification of psychological factors associated with adherence to self-care behaviors amongst patients with type 1 diabetes. J Diabet Res. 2019;2019:1-9. https://doi.org/10.1155/2019/6271591.

5. Stellefson M, Dipnarine K, Stopka C. Peer reviewed: The chronic care model and diabetes management in US primary care settings: A systematic review. Prev Chronic Disease. 2013;10:E26.

6. Bonger Z, Shiferaw S, Tariku EZ. Adherence to diabetic self-care practices and its associated factors among patients with type 2 diabetes in Addis Ababa, Ethiopia. Patient Preference Adheren. 2018;12:963.

7. Sarpooshi DR, Taghipour A, Mahdizadeh M, Peyman N. Enablers of and Barriers to Effective Diabetes Self-Care in Iran: A Qualitative Study. Patient Related Outcome Measures. 2020;11:109.

8. Alvarado-Martel D, Ruiz Fernández MÁ, Cuadrado Vigaray $M$, Carrillo $A$, Boronat $M$, Expósito Montesdeoca A, et al. Identification of Psychological Factors Associated with Adherence to Self-Care Behaviors amongst Patients with Type 1 Diabetes. J Diabet Res. 2019;2019:6271591.

9. Ida S, Kaneko R, Imataka K, Okubo K, Shirakura Y, Azuma K, et al. Effects of Flash Glucose Monitoring on Dietary Variety, Physical Activity, and Self-Care Behaviors in Patients with Diabetes. J Diabet Res. 2020;2020:9463648.

10. Lael-Monfared E, Tehrani H, Moghaddam ZE, Ferns GA, Tatari M, Jafari A. Health literacy, knowledge and self-care behaviors to take care of diabetic foot in low-income individuals: Application of extended parallel process model. Diabet Metabol Syndrome: Clin Res Rev. 2019;13(2):1535-41. 
11. Alhaiti AH, Senitan M, Dator WLT, Sankarapandian C, Baghdadi NA, Jones LK, et al. Adherence of Type 2 Diabetic Patients to Self-Care Activity: Tertiary Care Setting in Saudi Arabia. J Diabet Res. 2020;2020:4817637.

12. Reisi M, Mostafavi F, Javadzade H, Mahaki B, Tavassoli E, Sharifirad G. Communicative and critical health literacy and self-care behaviors in patients with type 2 diabetes. Iran $\mathrm{J}$ Diabet Metabol. 2015;14(3):199-208.

13. Seyedoshohadaee M, Barasteh S, Jalalinia F, Eghbali M, Nezami M. The relationship between health literacy and self-care behaviors in patients with type 2 diabetes. Iran J Nurs Res. 2016;10(4):43-51.

14. Guo X-m, Zhai X, Hou B-r. Adequacy of health literacy and its effect on diabetes self-management: a meta-analysis. Australian J Primary Health. 2021;26(6):458-65.

15. Gaffari-Fam S, Lotfi Y, Daemi A, Babazadeh T, Sarbazi E, Dargahi-Abbasabad G, et al. Impact of health literacy and self-care behaviors on health-related quality of life in Iranians with type 2 diabetes: a cross-sectional study. Health Q Life Outcom. 2020;18(1):1-9.

16. Yarmohammadi S, Momenyan S, Ghaffari M, Ali R, Azizpour M. Impact of functional, communicative and critical health literacy on glycemic control among patients with type 2 diabetes, and the mediating role of self-care. Psychology Res Behav Manag. 2019;12:427.

17. Rafferty AP, Winterbauer NL, Luo H, Bell RA, Little NRG. Diabetes Self-Care and Clinical Care Among Adults With Low Health Literacy. J Public Health Manag Pract. 2021;27(2):144-53.

18. Zhao F-F, Suhonen R, Katajisto J, Stolt M, Leino-Kilpi H. Association between diabetes-related selfcare activities and positive health: a cross-sectional study. BMJ Open. 2019;9(7):e023878.

19. Moradi F, Tourani S, Ziapour A, Abbas J, hematti M, Moghadam EJ, et al. Emotional Intelligence and Quality of Life in Elderly Diabetic Patients. Int Q Commun Health Educ. 2020:1-6 https://doi.org/10.1177/0272684X20965811.

20. Beverly EA, Ritholz MD, Dhanyamraju K. The buffering effect of social support on diabetes distress and depressive symptoms in adults with Type 1 and Type 2 diabetes. Diabet Med: J British Diabet Associat. 2020;42(5):e14472.

21. Kaboudi M, Dehghan F, Ziapour A. The effect of acceptance and commitment therapy on the mental health of women patients with type II diabetes. Ann Trop Med Public Health. 2017;10(6):1709-13 DOI: 10.4103/ATMPH.ATMPH_607_17.

22. Wang Y-X, Shan Z, Arvizu M, Pan A, Manson JE, Missmer SA, et al. Associations of Menstrual Cycle Characteristics Across the Reproductive Life Span and Lifestyle Factors With Risk of Type 2 Diabetes. JAMA Network Open. 2020;3(12):e2027928-e.

23. Zokaei A, Ziapour A, khanghahi M, Lebni J, Irandoost S, Toghroli R, et al. Investigating high blood pressure, type-2 diabetes, dislipidemia, and body mass index to determine the health status of people over 30 years. J Educ Health Promot. 2020;9(1):333. DOI:10.4103/jehp.jehp_514_20.

24. Castro AR, PeÃ \pm ate IL. Lifestyle in Patients with Type II Diabetes Mellitusof a Health Institution in Santa Marta, Colombia-2017. JOJ Nurs Health Care. 2019;11(1):7-13. 
25. Amer FA, Mohamed MS, Elbur Al, Abdelaziz SI, Elrayah ZA. Influence of self-efficacy management on adherence to self-care activities and treatment outcome among diabetes mellitus type 2. Pharmacy Pract (Granada). 2018;16(4):1082-90.

26. Hashemi SM, Bouya S. Treatment Adherence in Diabetic Patients: An Important but Forgotten Issue. J Diabet Nurs. 2018;6(1):341-51.

27. Chahardah-Cherik S, Gheibizadeh M, Jahani S, Cheraghian B. The relationship between health literacy and health promoting behaviors in patients with type 2 diabetes. Int $\mathrm{J}$ Commun Based Nurs Mid. 2018;6(1):65.

28. Al-Jumaili AA, Al-Rekabi MD, Sorofman B. Evaluation of instruments to assess health literacy in Arabic language among Iraqis. Res Soc Admin Pharmacy. 2015;11(6):803-13.

29. Hussein SH, Almajran A, Albatineh AN. Prevalence of health literacy and its correlates among patients with type II diabetes in Kuwait: A population based study. Diabet Res Clin Pract. 2018;141:118-25.

30. Toobert DJ, Hampson SE, Glasgow RE. The summary of diabetes self-care activities measure: results from 7 studies and a revised scale. Diabet care. 2000;23(7):943-50.

31. Mohamadzadeh S, Ezate G. A determination of self-care performance among diabetic patients in endocrine clinic of Taleghane hospital in Tehran. Iran J Nurs Res. 2014;8(4):8-11.

32. Shabibi P, Mansourian M, Abedzadehzavareh M, Sayehmiri K. The status of self-care behaviors in patients with type 2 diabetes in the city of Ilam in 2014. J Ilam Univ Med Sci. 2016;42(2):63-71.

33. Anbari K, Ghanadi K, Kaviani M, Montazeri R. The self care and its related factors in diabetic patients of khorramabad city. Yafteh. 2012;14(4):49-57.

34. Sorani M, Taghdisi M, Shojaei Z, Novin L, Noroozi M, Fallahi S. Predictors of self-care behaviors of patients with type 2 diabetes. J Health System Res. 2012;8(5):814-23.

35. Jordan DN, Jordan JL. Self-care behaviors of Filipino-American adults with type 2 diabetes mellitus. J Diabet Complicat. 2010;24(4):250-8.

36. Nouhjah S. Self-care behaviors and related factors in women with type 2 diabetes. Iran J Endocrinol Metabol. 2015;16(6):393-401.

37. Vaezi AA, Fallah B, Moshtagh Eshgh Z. The effects of basic conditioning factors on self-care behaviors of patients with type 2 diabetes referred to Yazd Research Center, 2014. J Shahid Sadoughi Univ Med Sci. 2018;25(10):770-9.

38. Farmer A, Wade A, French DP, Simon J, Yudkin P, Gray A, et al. Blood glucose self-monitoring in type 2 diabetes: a randomised controlled trial. Health Technol Assess. 2009;13(15):1-50.

39. Bai YL, Chiou CP, Chang YY. Self-care behaviour and related factors in older people with Type 2 diabetes. J Clin Nurs. 2009;18(23):3308-15.

40. Bukhsh A, Khan TM, Nawaz MS, Ahmed HS, Chan KG, Lee L-H, et al. Association of diabetes-related self-care activities with glycemic control of patients with type 2 diabetes in Pakistan. Patient Preference Adher. 2018;12:2377. 
41. Babazadeh T, Dianatinasab M, Daemi A, Nikbakht HA, Moradi F, Ghaffari-Fam S. Association of selfcare behaviors and quality of life among patients with type 2 diabetes mellitus: Chaldoran County, Iran. Diabet Metabol J. 2017;41(6):449.

42. Hu X, Hu X, Su Y, Qu M, Dolansky MA. The changes and factors associated with post-discharge selfcare behaviors among Chinese patients with heart failure. Patient Preference Adher. 2015;9:1593.

43. Davari L, Eslami AA. Underlying factors influencing self-care quality in type 2 diabetic patients in Khoram Abad City, Iran. J Res Develop Nurs Mid. 2014;11(2):77-85.

44. Cassimatis M, Kavanagh DJ, Smith AC. Perceived needs for supported self-management of type 2 diabetes: A qualitative investigation of the potential for a web-based intervention. Australian Psychologist. 2014;49(2):75-85.

45. Taghipour A, Moshki M, Mirzaei N. Determination of effective factors on self-care behaviors in women with diabetes referring to Mashhad health centers. Iran J Health Educ Health Promot. 2017;5(4):328-35.

46. Agha Molaei T, Eftekhar H, Mohammad K. Application of health belief model to behavior change of diabetic patients. Payesh. 2005;4(4):263-9.

47. Huisman S, de Gucht V, Maes S, Schroevers M, Chatrou M, Haak H. Self-regulation and weight reduction in patients with type 2 diabetes: A pilot intervention study. Patient Educ Counsel. 2009;75(1):84-90.

48. Najafi Ghezeljeh T, Ghasemi A, Rasouli M, Garak Yaraghi M. Correlations between Self-care Behaviors and Anxiety, Family Support, and Disease State in Patients with Heart Failure and Type II Diabetes Mellitus Admitted to Chamran Teaching Health Center in Isfahan, Iran (2018). Iran J Nurs. 2019;32(119):24-37.

49. Mohamadzadeh S, Ezate G. A determination of self-care performance among diabetic patients in endocrine clinic of Taleghane hospital in Tehran. Iran J Nurs Res. 2014;4(118-86).

50. Bigdeli MA, Hashemi Nazari SS, Khodakarim S, Brodati H, Mafi H. Factors associated with self-care behavior in patients with type ii diabetes. J Mazandaran Univ Med Sci. 2015;25(125):61-72.

51. Haire-Joshu D, Glasgow RE, Tibbs TL. Smoking and diabetes. Diabet Care. 2004;27:S74.

52. Parham M, Riahin A, Jandaghi M, Darivandpour A. Self care behaviors of diabetic patients in Qom. Qom Univ Med Sci J. 2012;6(4):81-7.

53. Sloan FA, Padrón NA, Platt AC. Preferences, beliefs, and self-management of diabetes. Health services Res. 2009;44(3):1068-87. 